\title{
Profil perdarahan uterus abnormal di RSUP Prof. Dr. R. D. Kandou Manado periode 1 Januari 2013 - 31 Desember 2014
}

\author{
${ }^{1}$ Muhammad Rifki \\ ${ }^{2}$ Maria Loho \\ ${ }^{2}$ Frank M. M. Wagey
}

\author{
${ }^{1}$ Kandidat Skripsi Fakultas Kedokteran Universitas Sam Ratulangi Manado \\ ${ }^{2}$ Bagian Obstetri Ginekologi Fakultas Kedokteran Universitas Sam Ratulangi Manado \\ Email: muh.rifki12041@gmail.com
}

\begin{abstract}
Abnormal Uterine Bleeding (AUB) is the most common cause of abnormal vaginal bleeding among women in reproductive age. Approximately $30 \%$ of women come to health care center with complaints of AUB during their reproductive period. The causes of AUB include a broad spectrum of diseases. The main classification of AUB according to FIGO has 9 categories of causes that is the acronym as "PALM-COEIN". This was a descriptive retrospective study using data of medical records of patients with abnormal uterine bleeding. The results showed that of: 51 cases with AUB, most were at the age of 41-50 years (24 cases; $47.06 \%$ ), with the youngest age was 14 years and the oldest age was 55 years. Most of the cases had normal body mass index, multiparity, and housewife. PALM-COEIN classification showed that most were leiomyoma (29 cases; 56.86\%) and ovulatory dysfuntion (11 cases; 21.57\%). Conclusion: Of the 51 patients with AUB at the Obstetrics and Gynecology Department of Prof. Dr. R. D Kandou Hospital Manado from January 2013 to December 2014, most cases were aged 41-50 years, multiparity, normal $\mathrm{BMI}$, leiomyoma, treatment with $\mathrm{D} \& \mathrm{C}$, and the pathological tesult was hyperplasia
\end{abstract}

Keywords: abnormal uterine bleeding (AUB)

\begin{abstract}
Abstrak: Perdarahan Uterus Abnormal (PUA) merupakan penyebab tersering perdarahan abnormal per vaginam pada masa reproduksi wanita. Sekitar 30\% wanita datang ke pusat pelayanan kesehatan dengan keluhan PUA selama masa reproduktif. Penyebab terjadinya PUA mencakup spektrum yang luas dari berbagai penyakit. Klasifikasi utama yang digunakan untuk PUA berdasarkan FIGO terdapat 9 kategori penyebab yaitu akronim dari "PALM-COEIN". Jenis penelitian ialah deskriptif retrospektif, dengan menggunakan data rekam medik pasien dengan PUA. Hasil penelitian memperlihatkan dari 51 kasus dengan PUA didapatkan paling sering pada usia 41-50 tahun sebanyak 24 kasus (47,06\%), dengan usia termuda 14 tahun dan usia tertua 55 tahun. Kasus PUA terbanyak dengan Indeks Massa Tubuh normal, paritas multipara, dan pekerjaan sebagai Ibu Rumah Tangga. Klasifikasi penyebab dengan PALM-COEIN sebagian besar ialah jenis leiomioma sebanyak 29 kasus (56,86\%) dan jenis ovulatory dysfuntion sebanyak 11 kasus (21,57\%). Simpulan: Dari 51 kasus PUA di Bagian Obstetri dan Ginekologi RSUP Prof. R. D. Kandou Manado kurun waktu Januari 2013 sampai Desember 2014 ditemukan terbanyak pada usia 41-50 tahun, multipara, IMT normal, jenis PUA leiomioma, pengobatan D \& C, dengan hasil PA hiperplasia.
\end{abstract}

Kata kunci: perdarahan uterus abnormal (PUA) 
Gangguan haid atau disebut juga dengan perdarahan uterus abnormal (PUA) merupakan keluhan yang sering menyebabkan seorang wanita datang berobat ke dokter atau tempat pertolongan pertama. Di RSUD Dr.Soetomo Surabaya pada tahun 2007 dan 2008 didapatkan angka kejadian perdarahan uterus abnormal sebanyak 12,48\% dan 8,8\% dari seluruh kunjungan poli kandungan. ${ }^{1}$

Gangguan haid ini mempunyai manifestasi klinis yang bermacam-macam tergantung kondisi serta penyakit yang dialami seorang wanita. Hampir semua wanita pernah mengalami gangguan haid selama masa hidupnya. Gangguan ini dapat berupa kelainan siklus atau perdarahan. Masalah ini dihadapi oleh wanita usia remaja, reproduksi dan klimakterik. ${ }^{2}$

Perdarahan Uterus Abnormal merupakan sebab tersering perdarahan abnormal per vaginam pada masa reproduksi wanita. Dilaporkan gangguan ini terjadi pada 5-10\% wanita. Lebih dari $50 \%$ terjadi pada masa perimenopause, sekitar $20 \%$ pada masa remaja, dan kirakira 30\% pada wanita usia reproduktif. Ras bukan faktor penting, tetapi insidensi leiomyoma pada wanita ras Afrika lebih tinggi dan mereka memiliki kadar estrogen yang lebih banyak, karena itu mereka cenderung untuk lebih sering mengalami episode perdarahan abnormal pervaginam. ${ }^{3}$

Secara klinis PUAl bukan merupakan masalah baru lagi karena penanggulangannya dapat dilakukan menurut gejala yang ditemukan. Dasar penanggulangannya ialah memperbaiki keadaan umum, menghentikan perdarahan dan mengembalikan siklus haid menjadi normal. Tetapi selama ini pengobatan terhadap PUA hanya bersifat simtomatis, sedangkan sesungguhnya pilihan pengobatan yang rasional ialah yang bersifat kausal dan berdasar pada patofisiologinya. $^{3}$

Perdarahan pervaginam yang sifatnya tidak normal sering dijumpai. Perdarahan tersebut dapat berhubungan dengan siklus haid ataupun tidak. Perdarahan yang didahului oleh haid yang terlambat biasanya disebabkan oleh abortus, kehamilan mola, atau kehamilan ektopik. Walaupun demikian, kemungkinan perdarahan karena polip servisis uteri, erosio porsio uteri, dan karsinoma servisis uteri tidak dapat disingkirkan begitu saja tanpa pemeriksaan yang teliti. Perdarahan dalam menopause perlu mendapat perhatian khusus karena gejala ini mempunyai arti klinik yang penting. ${ }^{4}$

PUA pada wanita tidak hamil di usia reproduktif memiliki patologi yang sangat luas. Terdapat banyak sekali terminologi yang digunakan baik untuk mendeskripsikan gejala maupun mengenai gangguannya sendiri sehingga dirasa cukup membingungkan dalam manajemen klinis dan dalam menerjemahkan sebuat riset dan uji klinis. ${ }^{5}$

PUA didefinisikan sebagai perdarahan dari korpus uteri meliputi semua kelainan haid baik dalam hal jumlah maupun lamanya. Hal ini digambarkan sebagai kronis kalau itu telah hadir untuk mayoritas 6 bulan sebelumnya, dan akut jika cukup berat perdarahan memerlukan pengobatan cepat atau intervensi. Manifestasi klinis dapat berupa perdarahan banyak, sedikit, siklus haid yang memanjang atau tidak beraturan. $^{5}$

Menstruasi dianggap normal bila perdarahan uterus terjadi setiap 21 - 35 hari dan tidak berlebihan. Durasi normal perdarahan menstruasi adalah anatar dua dan tujuh hari perdarahan uterus abnormal terjadi ketika baik frekuensi atau jumlah perdarahan uterus abnormal berbeda dari yang disebutkan diatas. ${ }^{6}$

Penyebab terjadinya perdarahan uterus abnormal dapat ditemukan diberbagai wanita dan usia, tetapi terkadang muncul pada saat saat tertentu antara lain: anovulasi (penyebab tersering), defek koagulasi, dan perimenopause (pemendekan fase proliferasi dan disfungsi korpus luteum). ${ }^{6}$

\section{Pola Perdarahan Uterus Abnormal}

PUA terjadi tanpa kelainan pada saluran reproduksi, penyakit medis tertentu atau kehamilan. ${ }^{7}$ Perdarahan akut dan banyak merupakan perdarahan menstruasi 
dengan jumlah darah haid $>1$ tampon per jam dan atau disertai dengan gangguan hipovolemik. ${ }^{7}$ Perdarahan ireguler meliputi metroragia, menometroragia, oligomenore, perdarahan haid yang lama (> 12 hari), perdarahan antara 2 siklus haid dan pola perdarahan lain yang ireguler. Pasien usia perimenars yang mengalami gangguan haid tidak dimasukkan dalam kelompok ini karena kelainan ini terjadi akibat belum matangnya poros hipothalamus - hipofisis - ovarium.

Menoragia merupakan perdarahan menstruasi dengan jumlah darah haid $>80$ cc atau lamanya $>7$ hari pada siklus yang teratur. Bila perdarahannya terjadi $>12$ hari harus dipertimbangkan termasuk dalam perdarahan ireguler. ${ }^{8}$

Perdarahan karena efek samping kontrasepsi dapat terjadi pada pengguna PKK, suntikan depo medroksi progesteron asetat (DMPA) atau AKDR. Perdarahan pada pengguna PKK dan suntikan DMPA kebanyakan terjadi karena proses perdarahan sela. Infeksi Chlamydia atau Neisseria juga dapat menyebabkan perdarahan pada pengguna PKK, sedangkan pada pengguna AKDR kebanyakan perdarahan terjadi karena endometritis. $^{8}$

\section{Klasifikasi}

Klasifikasi PUA terbagi menjadi 3 yaitu:

1. PUA akut: Perdarahan haid yang banyak sehingga perlu dilakukan penanganan yang cepat untuk mencegah kehilangan darah. PUA akut dapat terjadi pada kondisi PUA kronik atau tanpa riwayat sebelumnya. ${ }^{9}$

2. PUA kronik: Merupakan terminologi untuk PUA yang telah terjadi lebih dari 3 bulan. Kondisi ini biasanya tidak memerlukan penanganan yang cepat dibandingkan PUA akut. ${ }^{9}$

3. Perdarahan tengah (intermenstrual bleeding): terjadi di antara 2 siklus haid yang teratur. Perdarahan dapat terjadi kapan saja atau dapat juga terjadi di waktu yang sama setiap siklus. ${ }^{9}$
Berdasarkan International Federation of Gynecology and Obstetrics (FIGO), terdapat 9 kategori utama disusu sesuai dengan akronim "PALM COEIN" yakni ; polip, adenomiosis, leiomioma, malignancy dan hiperplasia, coagulopathy, ovulatory dysfunction, endometrial, iatrogenik, dan not yet classified. ${ }^{10}$

Kelompok PALM merupakan kelainan struktur yang dapat dinilai dengan berbagai teknik pencitraan dan atau pemeriksaan histopatologi antara lain: Polip, adenomiosis,lLeiomioma, dan malignancy and hyperplasia. Kelompok "COEIN" merupakan kelainan non strruktural yang tidak dapat dinilai dengan teknik pencitraan atau histopatologi. Sistem klasifikasi tersebut disusun berdasarkan pertimbangan bahwa seorang pasien dapat memiliki satu atau lebih faktor penyebab PUA antara lain Coagulopaty, Ovulatory dysfuntion, Endometrial, Iatrogenik, dan Not Yet Classified. $^{11}$

\section{Penatalaksanaan}

Pada dasarnya tujuan penatalaksanaan PUA ialah:Memperbaiki keadaan umum, Menghentikan perdarahan, dan Mengembalikan fungsi hormon reproduksi. ${ }^{12}$

Secara singkat langkah-langkah tersebut dapat diuraikan sebagai berikut:

1. Perbaikan keadaan umum: Pada perdarahan yang banyak sering ditemukan keadaan umum yang buruk. Pada keadaan PUA akut anemia yang terjadi harus segera diatasi dengan transfusi darah. Pada PUA kronis keadaan anemia ringan seringkali dapat diatasi dengan diberikan sediaan besi, sedangkan anemia berat membutuhkan transfusi darah. $^{13}$

2. Penghentian perdarahan: dapat dilakukan dengan pemakaian hormon steroid seks, penghambat sintesis prostaglandin, antifibrinolitik, pengobatan D \& C, dan pengobatan operatif. $^{14}$

3. Mengembalikan keseimbangan fungsi hormon reproduksi yang meliputi pengembalian siklus haid abnormal menjadi normal, pengubahan siklus 
Rifki, Loho, Wagey: Profil perdarahan uterus...

anovulatorik menjadi ovulatorik atau perbaikan suasana sehingga terpenuhi persyaratan untuk pemicuan ovulasi. ${ }^{15}$

\section{METODE PENELITIAN}

Jenis penelitian ini ialah deskriptif retrospektif dengan menggunakan data rekam medik pasien di RSUP Prof.dr.R.D. Kandou Manado. Subjek penelitian ialah penderita PUS di Bagian/SMF Obstetri dan Ginekologi RSUP Prof. dr. R.D. Kandou Manado selama periode 1 Januari 2013 31 Desember 2014.

\section{HASIL DAN BAHASAN}

Dari penelitian yang telah dilakukan bulan Oktober 2015 di Bagian Obstetri dan Ginekologi RSUP Prof. Dr. R. D. Kandou Manado ditemukan 51 kasus Perdarahan Uterus Abnormal (PUA). Data dikumpulkan dari rekam medik kemudian disajikan dalam bentuk tabel.

Pada Januari 2013 sampai Desember 2014 di Bagian Obstetri dan Ginekologi RSUP Prof. R. D. Kandou Manado (Tabel 1) ditemukan bahwa penderita PUA terbanyak pada usia 41-50 tahun sebanyak 24 kasus (47,06\%), diikuti oleh usia 31-40 tahun sebanyak 10 kasus, usia $\leq 20$ tahun sebanyak 7 kasus, usia 21-30 tahun sebanyak 6 kasus, usia 51-60 tahun sebanyak 4 kasus; tidak ditemukan pada usia $>60$ tahun. Dari penelitian yang telah dilakukan sebelumnya, prevalensi PUA dalam kelompok usia reproduksi sekitar $30 \%{ }^{10}$

Pada Tabel 1 dapat dilihat juga bahwa dari 51 kasus yang diteliti, paritas terbanyak ditemukan pada wanita dengan multipara sebanyak 34 kasus dan wanita dengan nulipara sebanyak 13 kasus. Indeks Massa Tubuh (IMT) pasien ditemukan terbanyak pada wanita dengan IMT normal. Berdasarkan pekerjaannya, profesi Ibu Rumah Tangga ditemukan sebanyak 34 kasus, pelajar sebanyak 7 kasus, PNS sebanyak 6 kasus dan swasta sebanyak 4 kasus.
Tabel 1. Distribusi penderita Perdarahan Uterus Abnormal berdasarkan karakteristik pasien

\begin{tabular}{|c|c|c|}
\hline Karakteristik & $\mathrm{N}$ & $\%$ \\
\hline \multicolumn{3}{|l|}{ Umur } \\
\hline$<20$ & 7 & 13,72 \\
\hline $21-30$ & 6 & 11,76 \\
\hline $31-40$ & 10 & 19,61 \\
\hline $41-50$ & 24 & 47,06 \\
\hline $51-60$ & 4 & 7,85 \\
\hline$>60$ & 0 & 0 \\
\hline Total & 51 & 100 \\
\hline \multicolumn{3}{|l|}{ Paritas } \\
\hline Nulipara & 13 & 25,49 \\
\hline Primipara & 4 & 7.84 \\
\hline Multipara & 34 & 66,67 \\
\hline Total & 51 & 100 \\
\hline \multicolumn{3}{|l|}{ IMT } \\
\hline$<18,5$ & 2 & 11,76 \\
\hline $18,5-24,9$ & 8 & 47,05 \\
\hline $25,0-29,9$ & 1 & 5,89 \\
\hline$>30,0$ & 6 & 35,29 \\
\hline Total & 17 & 100 \\
\hline \multicolumn{3}{|l|}{ Pekerjaan } \\
\hline IRT & 34 & 66,67 \\
\hline Swasta & 4 & 7,84 \\
\hline PNS & 6 & 11,76 \\
\hline Mahasiswa & 7 & 13,73 \\
\hline Total & 51 & 100 \\
\hline
\end{tabular}

Tabel 2. Distribusi penderita PUA berdasarkan Klasifikasi penyebab PALM-COEIN

\begin{tabular}{crc}
\hline PALM-COEIN & N & $\%$ \\
\hline Polip & 1 & 1,96 \\
Adenomiosis & 1 & 1,96 \\
Leiomioma & 29 & 56,86 \\
Malignancy dan Hyperplasia & 6 & 11,76 \\
Coagulopaty & 1 & 1,96 \\
Ovulatory Dysfuntion & 11 & 21,57 \\
Endometrial & 0 & 0 \\
Iatrogenik & 2 & 3,92 \\
Not Yet Classified & 0 & 0 \\
\hline Total & $\mathbf{5 1}$ & $\mathbf{1 0 0}$ \\
\hline
\end{tabular}

Pada Tabel 2 didapatkan bahwa penyebab PUA berdasarkan klasifikasi PALM-COEIN yaitu leiomioma (PUA-L) sebanyak 30 kasus (58,82\%), ovulatory dysfuntion (PUA-O) sebanyak 11 kasus (21,57\%), iatrogenik (PUA-I) sebanyak 2 kasus (3,92\%), polip (PUA-P), 
coagulopaty (PUA-C) dan adenomiosis (PUA-A) masing-masing 1 kasus (1,96\%), sedangkan endometrial dan not yet classified tidak ditemukan. Studi yang dilakukan di Afrika Selatan menyebutkan bahwa insidensi leiomioma pada wanita ras Afrika lebih tinggi dan mereka memiliki kadar estrogen yang lebih tinggi sehingga cenderung untuk lebih sering mengalami episode perdarahan abnormal pervaginam. ${ }^{8}$

Dari Tabel 3 didapatkan bahwa penanganan menggunakan Dilatasi dan Kuretase (D\&C) merupakan penanganan terbanyak dalam penanganan PUA

Tabel 3. Distribusi penderita PUA berdasarkan jenis penanganan

\begin{tabular}{crc}
\hline Penanganan & N & $\%$ \\
\hline Medikamentosa & 22 & 43,13 \\
D \& C & 25 & 49,02 \\
Operatif & 4 & 7,85 \\
Total & 51 & 100 \\
\hline
\end{tabular}

Dalam penelitian ini ditemukan sebanyak 25 kasus dengan penanganan D\&C, 22 kasus dengan pemberian medikamentosa, dan 4 kasus dengan penanganan operatif. Pada dasarnya pada PUA langkah ialah memperbaiki keadaan umum, termasuk pengatasan anemia. Langkah kedua ialah menghentikan perdarahan, baik secara hormonal maupun operatif. Setelah keadaan akut teratasi, sebagai langkah ketiga, dilakukan upaya pengembalian fungsi normal siklus haid dengan cara mengembalikan keseimbangan fungsi hormon reproduksi. ${ }^{13}$

Tindakan dengan teknik D\&C dapat menghentikan perdarahan karena menghilangkan daerah nekrotik pada endometrium. Dengan cara tersebut perdarahan akut berhasil dihentikan pada 40-60\% kasus. ${ }^{14}$

Pada Tabel 4 dapat dilihat dari 51 kasus PUA yang memiliki hasil Laboratorium PA hanya 4 kasus. Hasil Lab PA dengan Hiperplasia ditemukan sebanyak 2 kasus dan hasil lab PA dengan ketidakseimbangan hormonal dan $\mathrm{Ca}$ Endometrium masing-masing 1 kasus.
Tabel 4. Distribusi penderita Perdarahan Uterus Abnormal berdasarkan hasil PA

\begin{tabular}{|c|c|c|}
\hline Hasil PA & $\mathrm{N}$ & $\%$ \\
\hline Ketidakseimbangan Hormonal & 1 & 25 \\
\hline Hiperplasia & 2 & 50 \\
\hline Ca Endometrium & 1 & 25 \\
\hline Total & 4 & 100 \\
\hline
\end{tabular}

\section{SIMPULAN}

Dari hasil penelitian dan bahasan dapat disimpulkan bahwa dari 51 kasus Perdarahan Uterus Abnormal di Bagian Obstetri dan Ginekologi RSUP Prof. R. D. Kandou Manado kurun waktu Januari 2013 sampai Desember 2014 yang terbanyak ditemukan pada usia 41-50 tahun, multipara, IMT normal, jenis PUA leiomioma, pengobatan dengan $\mathrm{D} \& \mathrm{C}$, dan hasil PA ialah hiperplasia.

\section{SARAN}

Penderita dengan gejala perdarahan pada uterus yang abnormal agar lebih dini memeriksakan ke dokter spesialis Obstetri dan Ginekologi mengingat banyaknya jenis dari perdarahan uterus abnormal dengan penanganan yang berbeda-beda.

\section{DAFTAR PUSTAKA}

1. Hendarto H. Gangguan Haid/Perdarahan Uterus Abnormal. In: Mochammad Anwar, Ali Baziad, R. Prajitno Prabowo, editors. Ilmu Kandungan (3rd ed). Jakarta; PT Bina Pustaka Sarwono Prawirohardjo, 2011; p. 162-9.

2. Morgan G. Obstetri dan Ginekologi Panduan Praktik (2nd ed). Jakarta; EGC, 2009.

3. Elief P. Perdarahan Uterus Abnormal. 2012. [cited 21 Oktober 2015]. Available from:

http://perdarahanuterusabnormal.com/ article/manifestasi-klinis/.

4. Geffen D. Abnormal uterine Bleeding. 2011. [cited 21 Oktober 2015]. Available from:

http://cambridgemedicine.com/2011/0 2/15/907/.

5. Faizal M. Resiko Keganasan Perdarahan 
Rifki, Loho, Wagey: Profil perdarahan uterus...

Uterus Abnormal Berdasarkan Karakteristik Histopatologi Sediaan Kuretase Di RSUD DR. Moewardi Surakarta [Skripsi]. Surakarta: Universitas Sebelas Maret; 2015.

6. Livingstone M, Fraser S. Mechanisms of Abnormal Uterine Bleeding. 2010.h. 60-7. [cited 22 Oktober 2015]. Availabloe from: http://humupd.oxfordjournals.org/con tent/8/1/60.full.pdf.

7. John W. Abnormal Uterine Bleeding; A Management Algorithm. Journal Of The American Board Of Family Medicine. December 2010.h. 590602. [cited 22 Oktober 2015]. Available from: http://www.jabfm.org/content/19/6/59 0.full.

8. Egrave B. Epidemiology of abnormal uterine bleeding. Januari 2010.h. 88790. [cited 23 oktober 2015]. Journal and Research in Clinical Obstetrics and Gynaecology.

9. Baziad A, Hestiantoro A, Wiweko B. Panduan Tata Laksana Perdarahan Uterus Abnormal. Hasil Lokakarya Himpunan EndokrinologiReproduksi dan Fertilitas. Perkumpulan Obstetri dan Ginekologi Indonesia. Aceh, 2011.

10. Malcolm M, Hilary O.D. Critchley, Michael S Broder, Ian S Fraser.
FIGO Classification System (PALMCOEIN) for Causes of Abnormal Uterine Bleeding in Nongravid Women of Reproductive Age. American Society for Reproductive Medicine;April 2011.p. 3-13.

11. Obgynmag. Penanganan Perdarahan Uterus Abnormal Sebelum Menopause. Ilmu Kebidanan dan Penyakit Kandungan. Desember 2011. [cited 23 Oktober 2015]. Available from: http://obgynmag.0rg.co.id/2011/12/pe nanganan-perdarahan-uterusabnormal.html

12. Diagnosis of abnormal uterine bleeding in reproductive-aged women. American College of Obstetricians and Gynecologists; 2012.p.197-206.

13. The Royal College of Obstetricians and Gynecologist. The management of heavy menstrual bleeding. Nice Guideline; 2007.

14. Wilkinson JP, Kadir RA. Management of Abnormal Uterine Bleeding in adolescents. J Padiatr Adolesc Gynecol. 2010;23(6)(suppl):S22-S30.

15. Midwifery J. Abnormal Uterine Bleeding. Journal of Midwifery \& Women's Health. 2010. p. 191-3. [cited 22 Oktober 2015]. Available from: http://www.medscape.com/viewarticl e/717971. 